\title{
Molecular Detection and Antibiotic Sensitivity of Salmonella Species Isolated from Goat Feces in Sylhet District of Bangladesh
}

\author{
Md. Abdus Sabur, Mouri Rani Das, Md Bashir Uddin, Md. Mahfujur Rahman, Md. Rafiqul Islam, Md. Shahidur \\ Rahman Chowdhury, and Md. Mukter Hossain* \\ Department of Medicine, Faculty of Veterinary, Animal and Biomedical Sciences, Sylhet Agricultural University, Sylhet-3100, Bangladesh \\ *Corresponding author's Email: mukter.vetmed@sau.ac.bd; (DORCiD: 0000-0002-8506-1202
}

\begin{abstract}
The present study aimed at the molecular detection of Salmonella species from feces of goats and the characterization of the isolated Salmonella by biochemical and antimicrobial sensitivity techniques. A total of 220 goat feces samples were collected, of which 27 (12.27\%) were positive for Salmonella by conventional culture methods and $20(9.09 \%)$ by biochemical and PCR techniques. The prevalence was higher in goats under one year of age $(20 \%)$, compared to older animals aged one to two years $(7.8 \%)$ and more than two years of age $(4.7 \%)$, respectively. Moreover, the prevalence of diarrheic goats was significantly higher $(38.46 \%)$ than healthy animals $(2.76 \%)$. DNA was extracted from Salmonella strains and amplified by PCR using the specific primers of Salmonella invasion gene (invA gene). The antibiotic sensitivity test indicated that Ciprofloxacin (100 percent sensitivity), Gentamycin (100 percent sensitivity), and Neomycin (100 percent sensitivity) were the most effective antibiotics for the majority of Salmonella isolates. On the other hand, Salmonella isolates were found to have substantially high resistance to Erythromycin (100\%), Amoxicillin (100\%), Trimethoprim-Sulfamethoxazole (81.48\%), Streptomycin (62.96\%), and Tetracycline (55.56 percent). Since the rate of Salmonella carriers was relatively high, eating goat meat could increase the risk of foodborne salmonellosis.
\end{abstract}

Keywords: Antibiotic sensitivity, Goat isolation, PCR detection, Salmonella

\section{INTRODUCTION}

Capra aegagrus hircus, popularly the black Bengal goat domesticated in Bangladesh, preliminary reared for chevon by millions of poor women and landless peoples to increase poverty (Rahmanet al., 2017). Salmonellosis is one of the most important foodborne zoonoses all over the world. The pathogen has been isolated from the feces, lungs, and liver of goats worldwide (Ziinoet al., 2009). Salmonella can infect a wide range of animals, including poultry and other birds, horses, cattle, pigs, sheep, goats, dogs, cats, and reptiles (Songer and Post, 2004). These Gram-negative bacteria are mainly transmitted through contaminated food and water and are clinically characterized by septicemia and enteritis. However, the possibility of the upper respiratory tract bacterial transmission in the animal has been reported (Garg and Sharma, 1979). Salmonellosis in goats could occur at all ages during the year in both males and females and is responsible for the considerable loss of kids and may even cause abortion in adults (Arrudaet al., 2004). Salmonellosis is the most frequent disease in goats among the most common bacterial zoonotic diseases characterized by diarrhea (Radostits et al., 2007; Kahn et al., 2010). Detection of these organisms could be a serious public health concern (Adesiji et al., 2011).

The conventional laboratory cultural methods take a long time to achieve a positive or negative result. Molecular techniques, such as genetic probes and Polymerase Chain Reaction (PCR) enable rapid, sensitive, and pathogen identification in the atmosphere with precision (Josephson et al., 1991). Without displaying any clinical symptoms of salmonellosis, the infected animals may shed the Salmonella organism in their feces. As a result, a rapid, specific, and responsive Salmonella detection method is critical for animal and human health and as well as the diagnostic industry. Polymerase chain reaction detection of Salmonella in clinical samples from animals is faster than traditional culture techniques, with a sensitivity and specificity of 100 percent as compared to culture techniques. The method could be applied for rapid routine diagnosis (Stone et al., 1994). The objective of the present study was to estimate the prevalence of Salmonella in both diarrheic and healthy goats and to confirm it by PCR detection. 


\section{MATERIALS AND METHODS}

\section{Ethical statement}

This study was approved by the Ethical Committee of Sylhet Agricultural University, Sylhet-3100, Bangladesh, as well as by mutual (verbal) understanding of the respective farm owners.

\section{Geo-location of the study area}

The present study was conducted in the Sylhet district of Bangladesh, which is located in the northeastern part of Bangladesh. The average maximum and minimum temperatures were $38^{\circ} \mathrm{C}$ and $7{ }^{\circ} \mathrm{C}$, respectively. The present study was conducted over a 12-month period from January to December 2018 and the data regarding climatic conditions were retrieved from Regional Meteorological Centre, Sylhet, Bangladesh.

\section{Animals and samples}

A total of 180 black Bengal goats of different ages from the Government Goat Development Farm, Sylhet, and 40 goats from individual farmers in Sadar Upazilla, Sylhet, constituted the study population. Fecal samples were collected directly from the rectum of apparently healthy goats and stored refrigerated at $4^{\circ} \mathrm{C}$ until processed for nucleic acid purification within 24 hours of collection. A cross-sectional study was conducted to isolate and identify the Salmonella from the feces of goats.

\section{Salmonella isolation and identification}

The conventional bacteriological methods were used to isolate the Salmonella from the samples as described (Khan et al., 2021). The samples were inoculated into the nutrient broth and incubated at $37^{\circ} \mathrm{C}$ for 24 hours. Fecal samples were subjected to initial nutrient pre-enrichment and incubated, and $0.5 \mathrm{~mL}$ was transferred to $10 \mathrm{~mL}$ Tetrathionate Broth (Merck) and incubated at $37^{\circ} \mathrm{C}$ for 24 hours. Pre-incubated brilliant green and Xylose Lysine Deoxycholate (XLD) agar was streaked with a loop of each enrichment broth and incubated. The plates were then analyzed for the existence of Salmonella colonies. Suspected colonies were inoculated into TSI (Triple Sugar Iron agar), peptone water, Simmon's Citrate, Urea medium, and MR-VP.

\section{DNA extraction and PCR amplification}

The DNA extraction was performed according to the manufacturer's instruction using the Addprep genomic DNA extraction kit (Addbio Inc. Ltd., Korea). These eluted DNA samples were stored at $-80^{\circ} \mathrm{C}$ until further analysis. The PCR analysis was performed to detect the Salmonella invasion gene (invA gene) according to the manufacturer's instruction (Addbio Inc. Ltd., Korea). PCR assay performed in the thermal cycler TC1000G PCR System ${ }^{\circledR}$ (DLAB Scientific Inc., USA) with a heated lid. The cycling conditions included $50^{\circ} \mathrm{C}$ for 3 minutes (UDG Reaction), $95^{\circ} \mathrm{C}$ for 10 minutes (Initial Denaturation), 35 cycles of $95^{\circ} \mathrm{C}$ for 30 seconds (denaturation), $68^{\circ} \mathrm{C}$ for 45 seconds (annealing), and $72^{\circ} \mathrm{C}$ for 5 minutes for final extension (Khan et al., 2021). For the detection of Salmonella, the primers of invS-F (5'-TAA TGCCAGACGAAAGAGCGT-3') and invS-R (5'-GATATTGGTGTTTATGGG GTCGTT-3') were used (Khan et al., 2021). All reaction mixtures, including the negative control and Salmonella positive DNA, were tested in duplicate in the same run of PCR assay. PCR products were analyzed on $1.8 \%$ agarose gels stained with RedSafe ${ }^{\mathrm{TM}}$ (iNtRON Biotechnology, Korea) Nucleic Acid Staining Solution (20,000×), photographed, and stored as a digital image.

\section{Antimicrobial sensitivity testing}

The qualitative agar diffusion method (Kirby-Bauer method) was used for antibiotic sensitivity testing employing Mueller Hinton agar. The in vitro antibiotic sensitivity test was determined by the standard disc diffusion procedure according to the Clinical and Laboratory Standard Institute (CLSI, 2012). The antibiotic discs used in the present study were Erythromycin (ERY), Gentamycin (GEN), Streptomycin (STR), Amoxicillin (AMX), Ciprofloxacin (CIP), Tetracycline (TET), Neomycin (NM), and Trimethoprim-Sulfamethoxazole (SXT). The MIC (MIC50 and MIC90) was determined for each of the antibiotics used and the sensitivity or resistance was determined according to the protocol described (CLSI, 2012).

\section{Statistical analysis}

Microsoft Excel was used for the descriptive statistics. Chi-square tests were used to assess the significance of differences in prevalence between age, sex, and health status of the animals. $\mathrm{P}$ values less than 0.05 were considered significant using Chi-square tests (SPSS Inc., Chicago, IL, USA). 


\section{Prevalence of Salmonella in goats}

From January to December 2018, a total of 220 goat feces samples (180 from Government Goat Development Farm, Sylhet, Bangladesh, and 40 from different private goat farms in Sadar Upazilla in Sylhet) were collected for isolation and identification and molecular detection of Salmonella and antibiotic sensitivity testing. Among 220 samples, Salmonella isolates were detected in 27 (12.27\%) samples using the conventional cultural method. The isolates were followed by biochemical identification and PCR assays in which 20 (9.09\%) samples indicated Salmonella positive (Table 1). Furthermore, the prevalence of Salmonella in the personal private farm was lower (3.89\%) than the Goat development farm, Sylhet, which was estimated at 7.20\% (Table 2).

\section{Cultural and morphological characterization}

All Salmonella colonies in Mac Conkey agar plates appeared as non-lactose fermenters, colorless and transparent (Figure 1C), and Salmonella turbidity produced on nutrient broth (Figure1A). The isolates of Salmonella grown in Salmonella-Shigella (SS) agar plates indicated characteristic black-centered colonies (Figure 1B), but isolates were absent in the black dot. In microscopic analysis, the thin smears prepared with the colony from SS agar for Gram's staining showed Gram-negative, pink-colored, tiny rod-shaped appearance arranged in single or paired or short-chain (Figure 1D).

\section{Biochemical characterization}

Due to the cultural and morphological properties, all suspected Salmonella colonies were subjected to selected biochemical tests, including indole formation (Figure 2E), methyl red (Figure2B), and Voges Proskauer reaction (Figure 2C), citrate utilization, and triple sugar iron agar. Of the 27 suspected Salmonella colonies, 20 were confirmed by biochemical test results. On TSI slants, most of the Salmonella isolates indicated fermentation of glucose (Figure 2A), gas production from glucose, $\mathrm{H}_{2} \mathrm{~S}$ formation, but none of the isolates fermented either lactose or sucrose (Figure 2D).

\section{Antimicrobial susceptibility}

The antibiotic sensitivity test indicated that the highest number of Salmonella isolates were sensitive to Ciprofloxacin (100\%), Gentamycin (100\%), and Neomycin (100\%). Alternatively, there was significantly high resistance in Salmonella isolates to Erythromycin (100\%), Amoxicillin (100\%), Trimethoprim-Sulfamethoxazole (81.48\%), Streptomycin $(62.96 \%)$ followed by Tetracycline $(55.56 \%$, Table 3$)$.

\section{Detection of Salmonella by the polymerase chain reaction}

All Salmonella suspected cultures subjected to PCR amplification generated a product of approximate molecular size 100 base per (bp) (invA gene) according to the manufacturer's instruction (AddBio Inc., Korea). A 100 bp DNA marker was used as a molecular weight marker (AddBio Inc., Korea). The band size detected in isolated Salmonella was consistent as analyzed by agarose gel electrophoresis (Figure3). The estimated prevalence of Salmonella by using PCR was $9.09 \%(20 / 220)$ in goat feces.

Table 1. Overall prevalence of Salmonella isolates in goats according to biochemical identification at Sylhet district of Bangladesh

\begin{tabular}{|c|c|c|c|c|c|}
\hline Factors & Animal & $\begin{array}{c}\text { Number of } \\
\text { examined animals }\end{array}$ & $\begin{array}{c}\text { Positive fecal } \\
\text { samples }\end{array}$ & Prevalence & p value \\
\hline \multirow{3}{*}{ Age } & Up to 1 year & 45 & 9 & $20 \%$ & \multirow{3}{*}{$<0.01$} \\
\hline & 1 - 2 years & 90 & 7 & $7.8 \%$ & \\
\hline & $>2$ years & 85 & 4 & $4.7 \%$ & \\
\hline Total & & 220 & 20 & $9.09 \%$ & \\
\hline \multirow{2}{*}{ Sex } & Male & 150 & 9 & $6.0 \%$ & \multirow{2}{*}{0.321} \\
\hline & Female & 70 & 11 & $15.71 \%$ & \\
\hline Total & & 220 & 20 & $9.09 \%$ & \\
\hline \multirow{2}{*}{ Health status } & Apparentlyhealthy & 181 & 5 & $2.76 \%$ & \multirow{2}{*}{$<0.01$} \\
\hline & Diarrheic & 39 & 15 & $38.46 \%$ & \\
\hline Total & & 220 & 20 & $9.09 \%$ & \\
\hline
\end{tabular}

Level of significance $\mathrm{p}<0.05$ 
Table 2. Farm-level prevalence of Salmonella isolates in goats according to conventional cultural methods and biochemical identification in Goat development farm, Sylhet

\begin{tabular}{lccccc}
\hline Farm type & $\begin{array}{c}\text { Total number } \\
\text { of animal }\end{array}$ & $\begin{array}{c}\text { Number of positive by } \\
\text { conventional culture } \\
\text { methods }\end{array}$ & $\begin{array}{c}\text { Number of positive by } \\
\text { biochemical tests }\end{array}$ & $\begin{array}{c}\text { Conventional } \\
\text { methods }\end{array}$ & $\begin{array}{c}\text { Biochemical } \\
\text { /PCR tests }\end{array}$ \\
\hline SGDF* & 180 & 16 & 13 & $8.89 \%$ & $7.20 \%$ \\
IPF & 40 & 11 & 07 & $27.5 \%$ & $3.89 \%$ \\
Total & 220 & 27 & 20 & $12.27 \%$ & $9.09 \%$ \\
\hline
\end{tabular}

*Goat development farm, Sylhet, IPF: Individual private farm

Table 3. Overall susceptibility and resistance patterns of Salmonella isolates to selected antibiotics according to clinical and laboratory standard institute

\begin{tabular}{lllcc}
\hline Antimicrobial drug & Antimicrobial class & Abbreviation & Susceptible & Resistant* \\
\hline Amoxicillin & $\beta$-lactams & AMX & - & $100 \%$ \\
Ciprofloxacin & Quinolones & CIP & $100 \%$ & - \\
Trimethoprim-Sulfamethoxazole & Folate pathway inhibitors & SXT & $18.52 \%$ & $81.48 \%$ \\
Erythromycin & Macrolids & ERY & - & $100 \%$ \\
Gentamicin & Aminoglycosides & GEN & $100 \%$ & - \\
Neomycin & Aminoglycosides & NM & $100 \%$ & - \\
Streptomycin & Aminoglycosides & STR & $37.04 \%$ & $62.96 \%$ \\
Tetracycline & Tetracyclines & $44.44 \%$ & $55.56 \%$ \\
\hline
\end{tabular}

*Salmonella isolates that indicate moderate resistance to some antibiotics were considered resistant according to the CLSI recommendations.

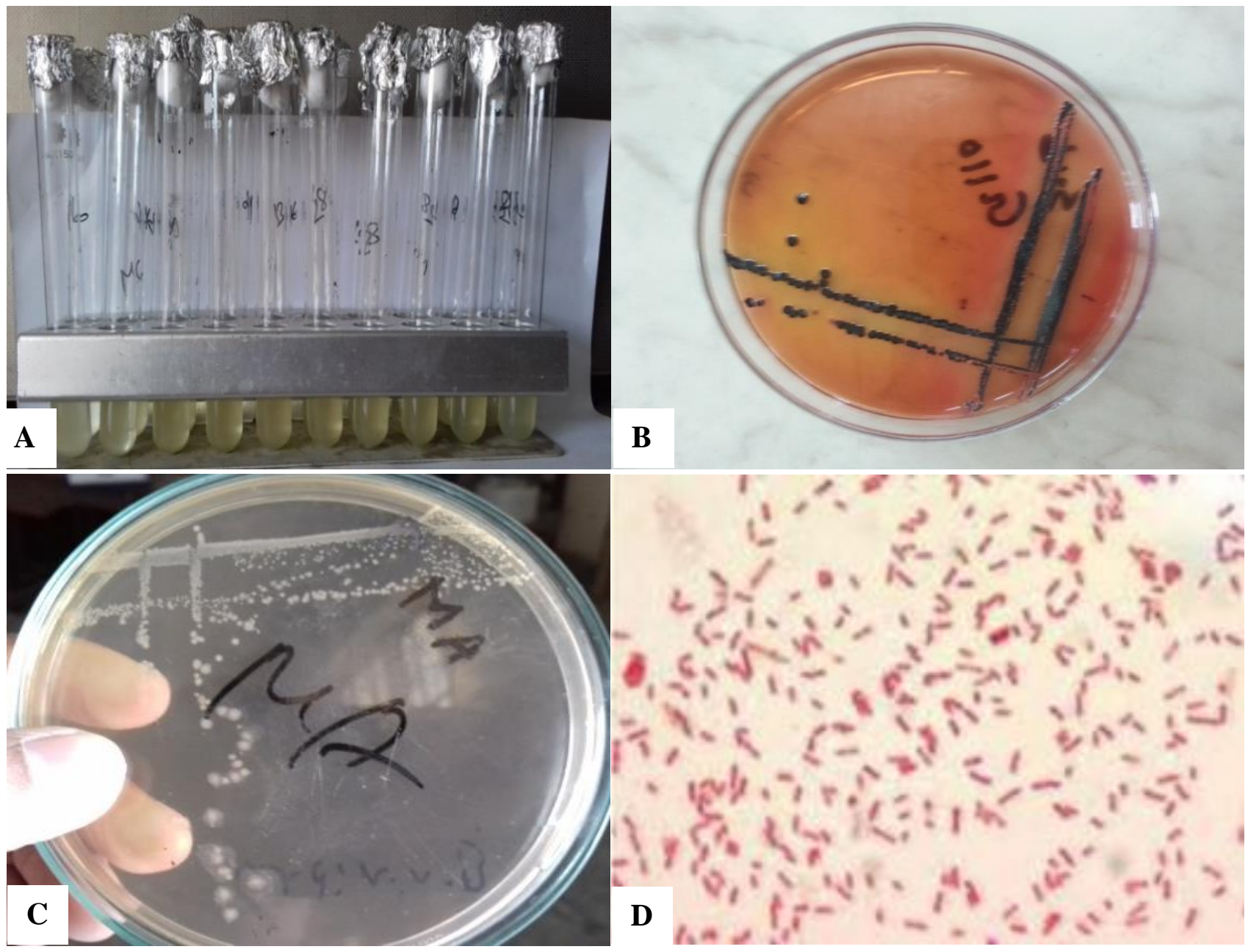

Figure1. A: Nutrient broth Salmonella produced turbidity, B: Black centered colony on Salmonella-Shigella (SS) agar, C: Colorless colonies on MacConkey agar, D: Gram staining under the microscope revealed Gram-negative, small rods arranged in single, paired, or clustered characteristics 


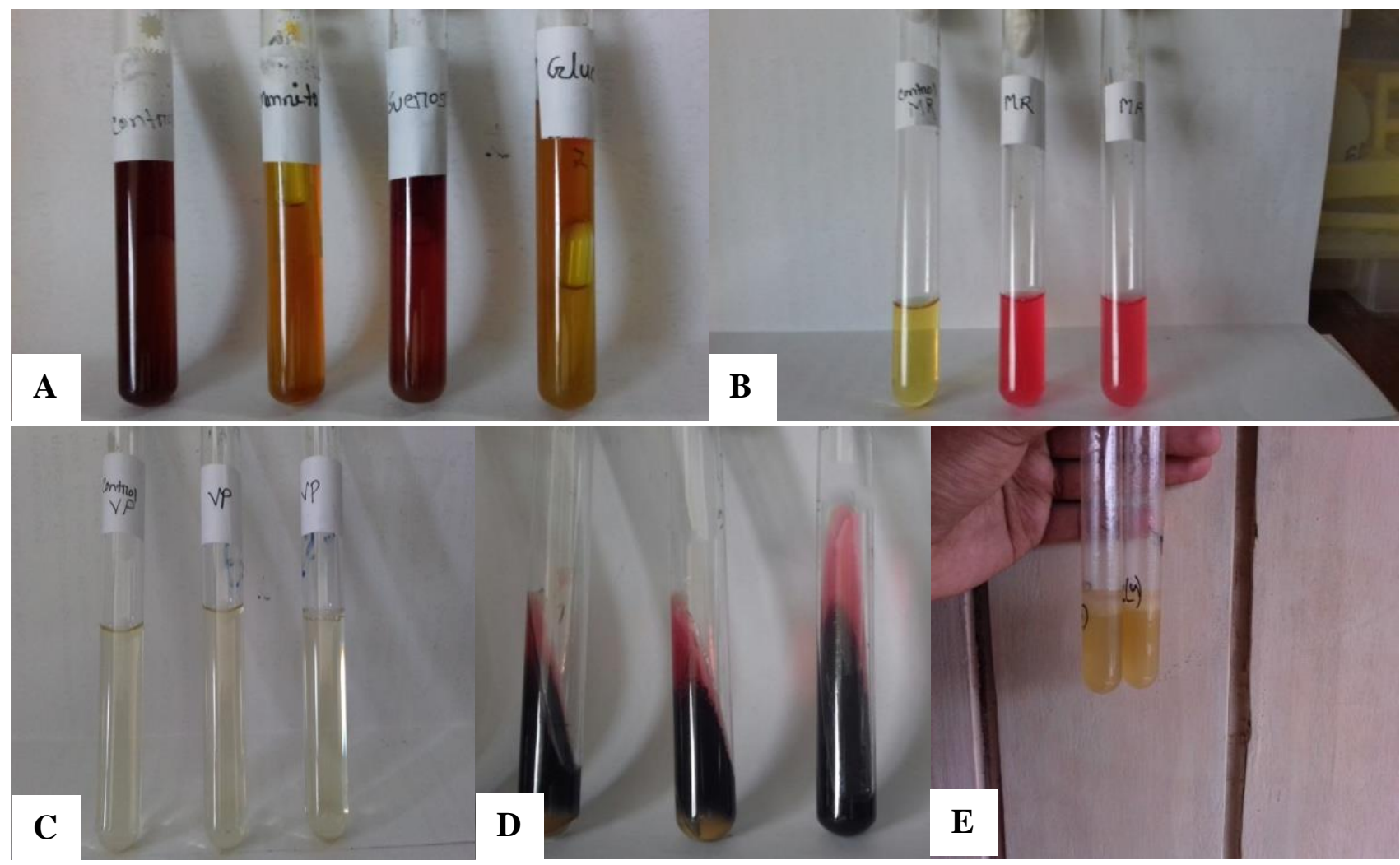

Figure 2. A: Sugar fermentation (Glucose and Mannitol +ve with the production of acid and gas, Sucrose -ve), B: MR Test (positive, red color), C: VP Test (Negative, no color change), D: TSI test (positive, Slant: red, butt: black); E: Indole Test (Negative, no color change)

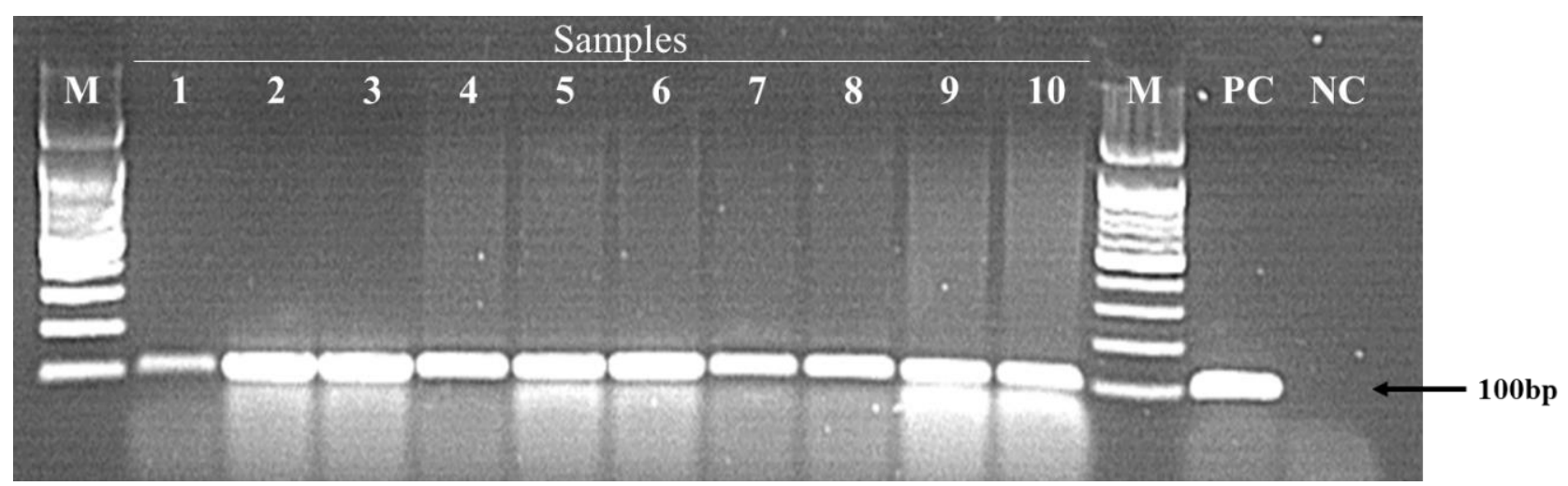

Figure 3. Results of PCR under UV illuminator (bands corresponding to the 100 bases per marker line indicated representative of Salmonella positive samples (1 10). M: Marker, NC: Negative control, PC: Positive control

\section{DISCUSSION}

The isolation and identification procedure included cultural examination, morphological examination, staining properties, biochemical tests, and molecular detection by PCR technique. In the present study, a total number of 220 feces samples from goats were collected by Sylhet Goat Development Farm (SGDF) and Individual Private Farm (IPF) in Sylhet. The bacteriological examination revealed the isolation of Salmonella organisms from goats with an estimated prevalence of $12.27 \%$ (27/220). Several studies reported a similar prevalence of Salmonella in goat feces (Teklu and Negussie, 2011; Saha et al., 2013; Bosilevac et al., 2015). The prevalence of Salmonella was higher in young (up to 1 year) and sick (diarrheic) animals, estimated to be $20 \%$ and $38.46 \%$, respectively. The age-related result of the present study is consistent with the findings of other researchers (Saha et al., 2013; Mahmood et al., 2014). The findings also coincide with the results of Hunduma et al. (2010), who stated diarrhea as the major problem in goats with a higher prevalence of $42.2 \%$.

A total of $20(9.09 \%)$ fecal samples were PCR positive for Salmonella, which is higher than others who reported only $1.05 \%$ PCR positive cases (Esmaeili and Rahmani, 2016). Similar studies were conducted on cattle in Bangladesh and found $8.50 \%$ positive by biochemical and PCR (Khan et al., 2021). In contrast, Teklu and Negussie (2011)found a higher prevalence of Salmonella in sheep and goats in an export abattoir in Ethiopia. They reported that $7.7 \%$ and $11.7 \%$ 
of the sheep and goats were positive for Salmonella. Gallegos-Robles et al. (2009) isolated and detected the Salmonella from cattle feces using microbiological and PCR methods, estimated the prevalence at 55\% and was much higher than in the present study. For the detection of Salmonella genus using the PCR technique, it was found that all PCR products of the isolated positive control resulted in 100 bases per amplified fragment. The invA gene has been reported to be present in all strains and clinical isolates of Salmonella (Dahshan et al., 2010). The detection of Salmonella in clinical samples by PCR results in a faster than conventional culture methods (Stone et al., 1994). The conventional method of isolating Salmonella is more laborious and requires more manpower (Van der Zee and Veld, 2000). There are a very small number of viable organisms in the feces that may fail to grow in artificial laboratory media. Molecular tests were most successful than conventional micro-biological techniques (Jungkind, 2001).

The antibiotic disk diffusion indicated that some isolates were resistant to Streptomycin (62.96\%), Amoxicillin (100\%), Erythromycin (100\%), trimethoprim/sulfamethoxazole (81.48\%), and Tetracycline (55.56\%). On the other hand, the highest number of Salmonella isolates was sensitive to Ciprofloxacin (100\%), Gentamycin (100\%), and Neomycin (100\%). Isolation of Salmonella from food and water to antibiotic resistance is of great importance in the case of public health. While these infections are caused by animal feces, it is also essential to identify the antibacterial agents that are used to treat or prevent infections, as well as the promoters that are created (Graham et al., 2007). It has been reported that a high percentage of Salmonella isolates from healthy and diseased animals were resistant to two or more antimicrobial agents (Esaki et al., 2004), which explains the high spread of these organisms through feces of apparently healthy animals and their wide dissemination in the environment. There have been reports of the release of $S$. Typhimurium in a pig plant (Tanaka et al., 2014). Although the animals were found to be healthy, the release was very high several days after inoculation; therefore even normal feces could be a source within the herd infection. It has been reported that multi-resistant S. Enteritidis (resistant to two or more antimicrobial agents) with different patterns could reach up to $51.6 \%$ (de Oliveira et al., 2005).

The most common patterns of resistance were sulfamethoxazole, streptomycin, and tetracycline while ciprofloxacin resistance was the least common. In Japan, S. Typhimurium isolated from various animal species indicated that $20 \%$ of the isolates were resistant to ampicillin and $24 \%$ to tetracyclines (Esaki et al., 2004). In 2008, 31 Salmonella strains were isolatedfrom 12 different serovars forms in cattle, and the transmission of microbial resistance from S. Heidelberg to S. Typhimurium and bacteriophages that are resistant to several beta-lactam antibiotics and tetracycline blaCMY-2, tet (A), and tet (B), was demonstrated (Zhang and LeJeune, 2008). Later, 58\% resistance to trimethoprim/sulfamethoxazole and $56 \%$ to tetracycline, followed by ampicillin and amoxicillin were reported (Yang et al., 2010). In Chile, in a preliminary study, $20.5 \%$ of the Salmonella strains isolated mainly from pigs, indicated multidrug resistance (MDR),with oxytetracycline being the drug with the highest resistance $(69.1 \%$, Junodet al., 2013).

\section{CONCLUSION}

From the findings of the present study, it could be concluded that Salmonella is an important cause of diarrhea in goats with salmonellosis in Bangladesh. Therefore, a rapid and proper diagnosis could prevent harm inflicted on the livestock industry. In this regard, the most accurate and quick diagnostic methods are required. The molecular basis of Salmonella identification techniques, such as the use of the invA gene-specific PCR method, could be useful in diagnostic and research laboratories. Ciprofloxacin, Gentamycin, and Neomycin might be the best choice among the antibiotics available on the market. The variation in antibacterial susceptibility or resistance pattern was also observed in the present study. This study suggests the strategic use of antibiotics for the control of Salmonella infections in animals.

\section{DECLARATIONS}

\section{Acknowledgment}

The authors acknowledge the Sylhet Agricultural University Research System (SAURES) for funding this research, and the respective farm owners for data support.

\section{Competing interests}

The authors have declared no conflict of interest regarding the publication of this research.

\section{Authors' contribution}

This manuscript is from the master's degree thesis of Md. Abdus Sabur. Md. Mukter Hossain designed the study. Md. Abdus Sabur and Mouri Rani Das conducted the experiments. All authors were involved in data interpretation, write up and final approval of the manuscript.

\section{Ethical considerations}

Ethical issues (including plagiarism, consent to publish, misconduct, data fabrication and/or falsification, double publication and/or submission, and redundancy) have been checked by the authors. 
Adesiji YO, Alli OT, Adekanle MA, andJolayemi JB (2011). Prevalence of Arcobacter, Escherichia coli, Staphylococcus aureus and Salmonella species in retail raw chicken, pork, beef and goat meat in Osogbo, Nigeria. Sierra Leone Journal of Biomedical Research, 3: 8-12. DOI: https://www.doi.org/10.4314/sljbr.v3i1.66644

Arruda SGB, Biscontini TMB, and Stamford TLM (2004). Microbiological characterization of goat meat subjected to different forms of management. Hygiene Alimentar, 18: 58-62. DOI: https://www.doi.org/10.12750/JET.2013.28.4.337

Bosilevac JM, Gassem MA, Al-Sheddy IA, Almaiman SA, Al-Mohizea IS, Alowaimer A, andKoohmaraie M (2015). Prevalence of Escherichia coli O157:H7 and Salmonella in camels, cattle, goats, and sheep harvested for meat in Riyadh. Journal of Food Protection, 78: 89-96. DOI: https://www.doi.org/10.4315/0362-028X.JFP-14-176

Clinical and Laboratory Standards Institute (CLSI) (2012). Performance standards for antimicrobial disk susceptibility tests; approved standard, 11th Edition CLSI document M02- A11. Wayne, PA: Clinical and Laboratory Standards Institute. https://www.clsi.org

DahshanH, Shahada F, Chuma T, Moriki H, and Okamoto K (2010). Genetic analysis of multidrug-resistant Salmonella enteric serovar Stanley and Typhimurium from cattle. Veterinary Microbiology,145:76-83. DOI: https://www.doi.org/10.1016/j.vetmic.2010.02.035

de Oliveira DS, Siqueira F, Ruschel L, andBrandelli A (2005). Antimicrobial resistance in Salmonella Enteritidis strains isolated from broiler carcasses, food, human and poultry-related samples. International Journal of Food Microbiology, 97: 297-305. DOI: https://www.doi.org/10.1016/j.ijfoodmicro.2004.04.022

Esaki H, Morioka A, Ishihara K, Kojima A, Shiroki S, Tamura Y, and Takahashi T (2004). Antimicrobial susceptibility of Salmonella isolated from cattle, swine and poultry (2001-2002): Report from the Japanese Veterinary antimicrobial resistance monitoring program. Journal of Antimicrobial Chemotherapy, 53: 266-270. DOI: https://www.doi.org/10.1093/jac/dkh081

Esmaeili H, and Rahmani HK (2016). Detection of Salmonella carriers in sheep and goat flocks of Bushehr and Lorestan Provinces, Iran. Journal of Medical Bacteriology, 5: 50-53. Available at: https://jmb.tums.ac.ir/index.php/jmb/article/view/256

Gallegos-Robles MA, Morales-Loredo A, Alvvarez-Ojeda G, OsunaGarcia JA, Martinez IO, Morales-ramos LH, and Fratamico P (2009). PCR detection and microbiological isolation of Salmonella spp. from fresh beef and cantaloupes. Journal of Food Science, 74: 37-40. DOI: https://www.doi.org/10.1111/j.1750-3841.2008.01006.x

Garg DN, and Sharma VK (1979). The detection of nasal carriers of Salmonella and other enterobacteria amongst young farm animals. Zentralblatt Bakteriologie Orig A, 243: 542-546. Available at: https://pubmed.ncbi.nlm.nih.gov/384721/

Graham JP, Boland JJ, and Silbergeld E (2007). Growth promoting antibiotics in food animal production: An economic analysis. Public Health Reports, 122: 79-87. DOI: https://www.doi.org/10.1177/003335490712200111

Hunduma D, Tigre W, Wagari M, and Regassa F (2010). Preliminary study on major health problems of the newly introduced boer goat breed in Ethiopia. World Applied Sciences Journal, 11: 803-807. Available at: https://www.cabi.org/ISC/abstract/2011319568

Josephson KL, Phillai SD, Way J, Gebra CP, and Pepper IL (1991). Fecal coliforms in soil detected by polymerase chain reaction and DNA-DNA hybridizations. Soil Science Society of America Journal, 55: 1326-1332. DOI: https://www.doi.org/10.2136/sssaj1991.03615995005500050022x

Jungkind D (2001). Automation of laboratory testing for infectious diseases using the polymerase chain reaction: Our past, our present, our future. Journal Clinical Virology, 20: 1-6. DOI: https://www.doi.org/10.1016/S1386-6532(00)00148-7

Junod T, Lopez-Martin J, and Gadicke P (2013). Antimicrobial susceptibility of animal and food isolates of Salmonella enterica. Revista Medica De Chile, 141: 298-304. DOI: https://www.doi.org/10.4067/S0034-98872013000300003

Kahn CM, Dana GA, Pete DC, Peter RD, Katherine EQ, Philip TR, Jagdev MS, Roger KW, and Tracee T (2010). The merck veterinary manual. 10th Edition. Merck and CO., Inc. USA. pp183, 287, 1898. 201. Available at: https://www.elsevier.com/books/the-merck-veterinary$\underline{\text { manual/major/978-0-911910-93-3 }}$

Khan MNK, Das MR, Sabur MA, Rahman MM, Uddin MB, Cho HS, and Hossain MM (2021). Isolation, identification, molecular detection and sensitivity to antibiotics of Salmonella from cattle faeces. Bulgarian Journal of Veterinary Medicine, 24: 57-66. DOI: https://www.doi.org/10.15547/bjvm.2019-0061

Mahmood AK, Khan MS, Khan MA, Khan MA, and Bilal M (2014). Prevalence of Salmonella in diarrheic adult goats in field conditions. The Journal of Animal and Plant Sciences, 24(1): 98-102. Available at:http://thejaps.org.pk/docs/v-24-1/15.pdf

Radostits OM, Gay CC, Hinchcliff KW, and Constable PD (2007). In: Veterinary Medicine, a textbook of the diseases of cattle, horses, sheep, pigs, and goats. Saunders, Elsevier Ltd, $10^{\text {th }}$ Edi, pp. 314, 316, 321, 898, 1541. Available at: https://www.elsevier.com/books/veterinarymedicine/radostits/978-0-7020-2777-2

Rahman MM, Hossain MM, and Miah MAM (2017). Poverty reduction and livelihood improvement of women through goat rearing. Asian Journal for Poverty Studies, 3: 59-66. Available at: https://ejournal.unib.ac.id/index.php/ajps/article/view/2672

Saha GK, Paul AK, Samad A, Islam MA, and Khan MSR (2013). Epidemiological investigation and antibiotic sensitivity of salmonellosis in goats at the selected areasof Bangladesh. Journal of Animal Reproduction and Biotechnology, 28: 337-342. Available at: http://www.ejarb.org/journal/view.html? volume $=28 \&$ number $=4 \&$ spage $=337$

Songer JG, and Post KW (2004). Veterinary microbiology: Bacterial and fungal agents of animal disease. 1st ed. St. Louis, MO: Elsevier Saunders, pp. 131-136. Available at: https://www.elsevier.com/books/veterinary-microbiology/songer/978-0-7216-8717-9

Stone GG, Oberst RD, Hays MP, McVey S, and Chengappa MM (1994). Detection of Salmonella serovars from clinical samples by enrichment broth cultivation-PCR procedure. Journal of Clinical Microbiology, 32: 1742-1749. DOI: https://www.doi.org/10.1128/JCM.32.7.1742-1749.1994

Tanaka T, Imai Y, Kumagae N, Sasaki T, and Ochiai N (2014). Quantitative microbiological evaluation of Salmonella Typhimuriumshed in diarrhea, loose, and normal stools of infected pigs. Open Journal of Veterinary Medicine, 4: 58-66. DOI: https://www.dx.doi.org/10.4236/ojvm.2014.44007

Teklu A, and Negussie H (2011). Assessment of risk factors and prevalence of Salmonella slaughtered small ruminants and environment in an export abattoir, Modjo, Ethiopia. American-Eurasian Journal of Sustainable Agriculture, 10(6): 992-999.

Van der Zee H, and Veld JHJH (2000). Method for the rapid detection of Salmonella, In: Salmonella in domestic animals, Wray C. and Wray A. (eds) CABI Publishing, Wallingford, UK, pp. 373-391. Available at: https://www.cabi.org/vetmedresource/ebook/20002210430

Yang B, Qu D, Zhang X, Shen J, and Cui S (2010). Prevalence and characterization of Salmonellaserovarsin retail meats of marketplace in Shaanxi, China. International Journal of Food Microbiology, 141: 63-72. DOI: https://www.doi.org/10.1016/j.ijfoodmicro.2010.04.015

Zhang Y, and LeJeune J (2008). Transduction of blaCMY-2, tet(A), and tet(B) from Salmonella enterica subspecies enteric serovar Heidelberg to S Typhimurium. Veterinary Microbiology, 129: 418-425. DOI: https://www.doi.org/10.1016/j.vetmic.2007.11.032

Ziino G, Giuffrida A, Bilei S, and Panebianco A (2009). Bacteria isolated from 25 hydatid cysts in sheep, cattle, and goats. Veterinary Record, 165: 234-236. DOI: https://www.doi.org/10.1136/vr.165.8.234 